\title{
Impact of Emotional Literacy Training on Students' Emotional Intelligence Performance in Primary Schools
}

\author{
Kerem Coskun (iD), , Yucel Oksuz (iD) 2 \\ ${ }^{1}$ Department of Primary Education, Artvin Coruh University, Artvin, Turkey \\ ${ }^{2}$ Department of Educational Sciences, Ondokuz Mayis University, Samsun, Turkey
}

\section{ARTICLE HISTORY}

Received: 31 March 2018

Revised: 01 December 2018

Accepted: 12 December 2018

\section{KEYWORDS}

Emotional Intelligence,

Emotional Literacy,

Primary School Students,

Social Development,

Emotional Development

\begin{abstract}
The present study seeks to reveal the impact Emotional Literacy Training (ELT) that lasted for two months, on students' emotional intelligence performance. The study was designed as a quasi-experimental research. The experimental group consisted of 16 students, while 12 students were assigned to control group. Data in pre-test and post-test were collected through the Ten Years Emotional Intelligence Scale (TYEIS) developed by Coskun, Oksuz and Yilmaz (2017). Data were analysed through the paired sample t-test and independent sample t-test. Findings of the study indicated that ELT significantly increased experimental group students' emotional intelligence performance and this significant increase remained permanently. Results were discussed according to Experiential Learning and Radical Behaviourism and in the light of relevant literature; several implications were developed for teachers, other school staffs and researchers.
\end{abstract}

\section{INTRODUCTION}

Emotions have a critical impact on mental health, morality, and spirituality, learning and cognitive functions. Therefore, social and emotional skills are key components of the educational process to sustain children's developmental process, conduct an effective instruction. The fact that emotional skills are so crucial that requires conceptualization and systematic instruction.

Emotional intelligence is one of the conceptualizations related to social-emotional skills. Emotional intelligence can be described as a construct which consists of self-awareness, appropriate explanation of emotions, self-regulation, motivation, and establishing positive relationships with others. There are three emotional intelligence models. Those are the ability model, the mixed models, and the trait model (Matthews, 2006). 
Goleman (1998) proposed an emotional intelligence model. It has five sub-dimensions as selfawareness, self-management, empathy, motivation, and social skills. Self-awareness is the skill to accurately recognize and label emotions in self. Self-management skill is the capacity to effectively cope with emotions. Empathy is a very crucial skill in the model because empathy has a function to establish and prolong constructive relationships with others. Empathy can be described as a social skill to recognize emotions in others understand and respond them. Therefore, Goleman (1998) sees empathy as social radar. Motivation is the skill which includes motivation drive, commitment, initiation, and optimism (Boyatzis, Goleman, \& Rhee, 2000). Social skills are the skills which help the individual to establish cooperative and positive relationships with others and sustain these relationships. Social skills consist of influence, conflict management, leadership, change catalyst, building bonds, collaboration and cooperation, and team capabilities (Boyatzis, Goleman \& Rhee, 2000).

Emotional literacy, developed by Steiner (1979) is another term about the emotional and social world. Steiner (1979) defined emotional literacy as a construct which includes accurate recognition of emotion in self, empathy, suitable express of emotions to others, and emotion management. Steiner (1979) divides the emotional literacy into five skills. Those are knowing emotions, possession of a sense of empathy, management of emotions, the resiliency of emotional damage, and combining those skills.

Faupel (2003) practically addressed emotional literacy and developed an emotional literacy model. Faupel Emotional Literacy Model consists of self-awareness, self-regulation, motivation, social competence, and social skills. Self-awareness is the skill which helps to label and name emotions. Self-regulation emphasizes learning to control emotions and modify behaviours. Motivation is another component of the emotional literacy. Motivation enables students to determine a goal and initiate to act. In Faupel's Emotional Literacy Model, social competence means empathy as a skill to understand others' emotions needs, and concerns. Social skills include conflict resolution, influence, communication, and leadership, change catalyst, building bonds, team capabilities, collaboration and cooperation.

There may be confusion between emotional intelligence and emotional literacy. Moreover, both of the concepts may be used interchangeably each other. Emotional intelligence is preferred to use in the USA, educators in the UK opt for the emotional literacy. There are differences between the two concepts, even though emotional literacy and emotional intelligence have similar characteristics. The concept of intelligence means the individual capacity to progress either cognitive information or socio-emotional information, where the term of literacy emphasizes possession of linguistic skills and strategy about how linguistic skills are put into practice in order to exchange ideas with others and overcome language barriers in daily living. In other words, literacy centres on possession of skills and strategic insight about their practice while intelligence makes an emphasis potential capacity to progress information (Matthews, 2006). Emotional intelligence has individualistic characteristics about a progression of socioemotional information. Emotional literacy can be considered as an instruction and strategy in which student is taught socio-emotional skills (Orbach, 1998; Tew, 2007; Pratt, 2009). Social and emotional Aspect of Learning (SEAL) conducted in England, Promoting alternative Thinking Strategies (PATHS) and Collaborative for Academic, Social and Emotional Learning (CASEL) are instructional curriculums whose purpose is to teach socio-emotional skills in schools. Therefore, those curriculums are known as emotional literacy programs (Goleman; 1995; Park, 1999; Perry, Lennie \& Humphrey, 2008; Burman, 2009; Hallam, 2009; Pratt, 2009; Flynn, 2010; Gillum, 2010). The more educational goals about social and emotional learning are included, the more classroom time is allocated to teach social and emotional skills contemporary instructional curriculums. 
A few number of the research indicated that increase in emotional intelligence performance of students has positive outcomes in academic achievement, more competency to cope with depression, better adjustment, and social support (Qualter, Whiteley, Hutchinson \&Pope, 2007; Hallam, 2009; Ferrando et al., 2010; Di Fabio \& Kenny, 2011; Jellesma, Rieffe, Terwogt \& Westenberg, 2011; Rivers et al., 2012). In the present study, it was expected that teaching emotional intelligence skills from Goleman's emotional intelligence model through emotional literacy training designated by the researchers, may reveal beneficial outcome for children who are at the end of primary school period. Furthermore, there is a close relationship between emotional intelligence and spirituality (Paek, 2006). Improving emotional intelligence through emotional literacy activities can lead to better spirituality, well-being, and social functioning. Therefore, instructional emotional literacy activities may trigger the development of spirituality skills among primary school children (Emmons, 2000).

Purpose of the study: Schools aim to develop social-emotional skills as well as cognitive skills of students. Emotional intelligence is a concept that should be fostered in schools in the context of social-emotional skills. Development of emotional intelligence skills allows students to recognize and express their emotions in a constructive way, cope with stringent emotions, develop sense of empathy, and establish positive relationships with others. However, development of emotional intelligence skills entails systematic and planned instruction.

Concept of emotional intelligence defines necessary skills for social-emotional adjustment but it does not offer any explanation about how to teach and foster the skills. Emotional literacy offers an explanation about how to teach. In the UK and the USA the SEAL, the CASEL, and the PATHS are emotional literacy programs that foster emotional intelligence skills in schools from primary schools to highs schools (Goleman; 1995; Park, 1999; Perry, Lennie \& Humphrey, 2008; Burman, 2009; Hallam, 2009; Pratt, 2009; Flynn, 2010; Gillum, 2010).

In Turkey, social-emotional skills are dealt with in life knowledge and social studies courses. However, emotional intelligence is taught within limited duration and there is no systematic and planned teaching approach. Although there are a few studies that develop social skills, emotional intelligence in Turkey, but those studies were conducted with research participants who had been isolated from their previously established social interactions (Arda \& Ocak, 2012; Saltal1, 2011; Ulutaş, 2005; Yaşarsoy, 2006). Purpose of emotional literacy is to develop socialemotional skills of students based on their social interactions and without isolating from classroom environments. In the present study, a specific emotional literacy training program was developed and conducted with primary school participants without isolating from their classroom environments, and its impact was explored. As a result of the present study, it was sought out modelling an emotional literacy training and offering practical implications for Turkish primary education system.

\section{METHOD}

Design of the Research: The present study was designed in experimental research, one of the quantitative research traditions, because of the fact that the present study aims to reveal the impact of the ELT, seeks causation between the ELT and scores of the emotional intelligence performance of the participant primary school children. In experimental researches, the impact of an independent variable upon dependent variable is sought to reveal. For this reason, the experimental group was manipulated by ELT, independent variable of the study, while the control group received no manipulation. Participant students were not randomly and individually assigned to the groups because of the fact that the emotional literacy training depends on previously established interaction among the students. The present study was designed in quasi experimental research due to the impossibility of random assignment to the groups (Cohen, Manion, \& Morrison, 2000; Frankel, Wallen, \& Hyun, 2012). 
Selection of the Research Participants: Convenience sampling was used because of the fact that random selection of the participant was impossible. Emotional literacy depends on previously established social interaction among the participants. This notion prevented random selection and creation of a new study group. Research participants were selected according to voluntary participation of primary school children and their teachers, classroom size, ages of the participants. Classroom size was as crucial as voluntary participation, because of the fact that ELT depends on a careful focus on interaction, active participation, discussion instructional experience in depth, and sharing thoughts and emotions with others. Therefore, it was decided that a maximum number of the members in both of the groups should not exceed 20 . On the other hand, measurement of emotional intelligence was carried out through self-report, and selfreport depends on sincere and accurate response without any bias. Primary school children who are 10 years old are more adept to sincerely and accurately evaluate the items on the TYEIS. Therefore, it was decided that primary school children at the age of 10 , would be included in the study. Before consulting primary school children and their teachers, necessary official permission was taken from local education authorities in Turkey. Upon receiving official permission, the researchers visited primary schools, met teachers and primary school children, explained what would be conducted. Two primary school teachers and their children accepted to participate in the study. The groups were matched through their scores from the TYEIS developed by Coskun, Oksuz \& Yilmaz (2017). As a result of the application of the TYEIS as a pre-test, 16 students whose age is 10 , were assigned to the experiment group while the control group consisted of 12 students whose age is 10 years. In the experiment group, 7 of primary school children were female while 9 of them were male. In the control group, 6 of the primary school children were female whereas 6 of them were male.

In order to test whether the groups were equal to each other and parametric or non-parametric test would be used, normality test was conducted. Shapiro-Wilk test was used in the normality test because of fewer students in the groups than 30 (Shapiro-Wilk, 1965). Results of the normality test were indicated in Table 1.

Table 1. Result of the Normality Test

\begin{tabular}{llccccc}
\hline Measurement & Groups & $\mathrm{n}$ & $\begin{array}{c}\text { Shapiro-Wilk } \\
(\mathrm{S}-\mathrm{W})\end{array}$ & $\bar{X}$ & $\mathrm{Df}$ & $\mathrm{Sd}$ \\
\hline $\begin{array}{l}\text { Total Score from the } \\
\text { TYEIS }\end{array}$ & Experiment & 16 & .11 & 22.50 & 16 & 1.36 \\
\cline { 2 - 7 } & Control & 12 & .98 & 23.08 & 12 & 3.06 \\
\hline
\end{tabular}

Normality test analysis indicated that the data has a normal distribution. As a result of the normal distribution, a comparison between both of the groups was made through the independent t-test (Field, 2009).

Table 2. Results of Independent T-Test

\begin{tabular}{|c|c|c|c|c|c|c|c|}
\hline Measurement & Groups & $\mathrm{n}$ & $\bar{X}$ & Ss & $\mathrm{Sd}$ & $\mathrm{t}$ & $\mathrm{p}$ \\
\hline \multirow{2}{*}{$\begin{array}{l}\text { Total Score from the } \\
\text { TYEIS }\end{array}$} & Experiment & 16 & 22.50 & 1.36 & \multirow[b]{2}{*}{26} & \multirow[b]{2}{*}{-.68} & \multirow[b]{2}{*}{.49} \\
\hline & Control & 12 & 23.08 & 3.02 & & & \\
\hline
\end{tabular}

Results of independent t-test revealed that there is no significant difference between the groups in total scores of the TYEIS $\left(\mathrm{t}_{(26)}=-.68, p>0.05\right)$. Therefore, it was concluded that the experiment group and the control group were equal to each other in pre-test measurement. 
Components of The Emotional Literacy Training Activities: ELT Activities were designed for self-awareness, self-regulation, motivation, empathy, and social skills. In the self-awareness activities, the participant children's emotional vocabulary was expanded by displaying human faces, circle time discussions, work-sheets to which they responded the questions about environment and emotions. In ELT Activities for self-regulation skill, the participant children learnt to how to manage emotions and modify behaviours through criticise, competition, puzzle games. ELT Activities for motivation skill helped the participant children handle with excitement so as to be motivated through classroom-based competitions and follow-up discussions. ELT Activities for empathy skill fostered empathy among the participant children by pairing each other, stories. In the social skill activities, participant children constituted groups and cooperated in order to design a poster, contemplated on the events on which one of them did a favour for another friend, and produced "the Sharing Tree". Furthermore, at the end of each of the activities, each participant children stated what they had felt, thought, behaved.

The Process: There is a close similarity between Goleman Emotional Intelligence model and Faupel Emotional Literacy Model in terms of categorizing social and emotional skills so the two models were integrated into the present study. The researchers investigated Goleman Emotional Intelligence Model and they decided which social-emotional skills would be taught during ELT. On the other hand, Faupel Emotional Literacy Model inspired the researchers how the social-emotional skills would be taught. In other words, the social-emotional skills from Goleman Emotional Intelligence Model set instructional goals, while emotional literacy model by Faupel (2003) functioned as instructional ways how to teach. 16 social and emotional skills were determined as instructional aims; 18 instructional activities were designed to teach those skills. A pilot study was conducted in the 2013-2014 instructional year between March and June. After pilot study, it was concluded that 18 instructional activities were decreased to 16 instructional activities. As a result of the pilot study, duration of the activities revised and more classroom time was allocated to students to state their emotions and experiences which they underwent in the activities.

Before the ELT, the TYEIS were applied on both of the groups as the pre-test. The experimental group received the ELT during 8 weeks. ELT lasted for 31-course hours during 8 weeks. ELT was administered by the researcher. The control group received no treatment so previously planned and ordinary classroom activities were applied to the control group. After ELT had finished, participant students from both the experimental groups and the control group took the TYEIS as post-test. The TYEIS were again given to the participant students in both of the groups as follow-up test.

The Instruments: Emotional intelligence performance of the participant students was assessed through the TYEIS developed by Coskun, Oksuz \& Yilmaz (2017). The TYEIS measures social and emotional skills in the Goleman emotional intelligence model. It consists of ten items with one dimension. In the TYEIS the items have three response choices as "not true", "somewhat true", and "completely true". All of the items are so negative that they were reversely graded. The highest point is 30 and the lowest point is 10 in the TYEIS. Its reliability coefficient is .89 and it has also good model fitting indices (RMSEA = .06, CFI=.97, IFI=.97, RFI= .93, $\mathrm{GFI}=.95, \mathrm{AGFI}=.94, \mathrm{NFI}=.95, \mathrm{SRMR}=.03$ ).

\section{FINDINGS}

Levene test was carried out in so as to test homogeneity assumptions. Results of Levene test were indicated in Table 3.

Result of Levene test indicated that homogeneity assumption was confirmed for both the scores of the experiment group and that of the control group in the TYEIS. Homogenous variance in both of the groups' scores enabled using Analysis of Covariance (ANCOVA) to compare 
emotional intelligence performance of the experiment group to emotional intelligence performance of the control group. Moreover, ANCOVA helps to reduce the error variance and allows assessing more precisely the impact of ELA, independent variable of the study (Field, 2009; Tabachnik \& Fidell, 2012). Therefore, due to homogenous variances, reduction in the error variance, and more precise assessment of the ELA, ANCOVA was used to identify impact of the ELA. ANCOVA results were displayed in Table 4.

Table 3. Homogeneity Test Through Levene Test

\begin{tabular}{lllll}
\hline Measurement & $\mathrm{F}$ & $\mathrm{Sd}_{1}$ & $\mathrm{Sd}_{2}$ & $\mathrm{P}$ \\
\hline TYEIS & 7.10 & 1 & 26 & .073 \\
\hline $\mathrm{P}=.05$ & & & &
\end{tabular}

Table 4. ANCOVA Results

\begin{tabular}{lcccccc}
\hline Factor & SS & Df & MS & F & P & $\eta^{2}$ \\
\hline $\begin{array}{l}\text { Corrected } \\
\text { Model }\end{array}$ & 228.47 & 2 & 76.13 & 7.71 & .001 & .49 \\
\hline Intercept & 26.54 & 1 & 26.54 & 2.68 & .114 & .10 \\
\hline TYEIS $_{\text {pre-test }}$ & 20.95 & 1 & 20.95 & 2.12 & .158 & .08 \\
\hline Group & 186.35 & 1 & 186.33 & 18.86 & .001 & .44 \\
\hline Error & 237.01 & 25 & 9.87 & & & \\
\hline Total & 594.00 & 28 & & & & \\
\hline Corrected Total & 465.42 & 27 & & & & \\
\hline
\end{tabular}

Findings from Table 4 indicated that there is a significant difference between the experimental group students' total score of the TYEIS and that of the control group student and the ELT significantly increased experimental group students' emotional intelligence performance $\left(\mathrm{F}_{(1}\right.$, 25) $\left.=18.86, \mathrm{p}<.05, \eta^{2}=.44\right)$.

Follow-up test was administered on both of the groups two months later. In order to test homogeneity assumption Levene test was conducted. Levene test results about the follow-up test were shown in Table 5.

Table 5. Homogeneity Test Through Levene Test

\begin{tabular}{lllll}
\hline Measurement & $\mathrm{F}$ & $\mathrm{Sd}_{1}$ & $\mathrm{Sd}_{2}$ & $\mathrm{P}$ \\
\hline TYEIS & 7.07 & 1 & 26 & .06 \\
\hline
\end{tabular}

$\mathrm{P}=.05$

Findings related to Levene test of the follow-up test indicated that variances in the experimental group and the control group are homogeneous. As result of the Levene test, it was decided that data are suitable to conduct ANCOVA in order to detect whether significant difference between the groups exists and the impact of the ELT is permanent (Field, 2009; Tabachnik \& Fidell, 2012). Findings of ANCOVA were indicated in Table 6.

Findings of ANCOVA indicated that there is a significant difference between experimental group students' total score and the control group students' total score in favour of the experimental group students $\left(\mathrm{F}_{(1,25)}=19.69, \mathrm{p}<.05, \eta^{2}=.44\right)$. The significant difference emerged by the ELT in the post-test, continues to exist in the follow-up test. 
Table 6. ANCOVA Results Follow-Up About Follow-Test

\begin{tabular}{lcccccc}
\hline Factor & SS & Df & MS & F & P & $\eta^{2}$ \\
\hline $\begin{array}{l}\text { Corrected } \\
\text { Model }\end{array}$ & 228.47 & 2 & 114.20 & 12.09 & .00 & .49 \\
\hline Intercept & 29.45 & 1 & 29.43 & 3.10 & .09 & .11 \\
\hline TYEIS & & & & & & .14 \\
\hline pre-test & 20.97 & 1 & 20.97 & 2.21 & .08 \\
\hline Eroup & 186.68 & 1 & 186.68 & 19.69 & .00 & .44 \\
\hline Total & 237.02 & 25 & 9.48 & & & \\
\hline Corrected Total & 594.00 & 28 & & & & \\
\hline
\end{tabular}

\section{DISCUSSION}

In the study, it was observed that ELT increased significantly experimental group's emotional intelligence performance while control group student's emotional intelligence performance did increase. Results support the notion that students' emotional intelligence performance can be developed through interventional programs and instructional activities. Results of the study are supported by several findings of the research in the literature ((Bredacs, 2010; Brown, 2003; Coppock, 2007; Di Fabio \& Kenny, 2011; Dolev, 2012; Domitrovich, Cortes \& Greenberg, 2007; Dulewicz \& Higgs, 2004; Gillum, 2010; Haddon, Goodman, Park \& Crick, 2005; Perry et al., 2008; Hallam, 2009; Hamre, Pianta, Mashburn \& Downer, 2012; Kelly, Longbottom, Pots \& Williamson, 2004; Lu \& Buchanan, 2014; O'Hara, 2011; Zeidner, Roberts \& Matthews, 2002). 10 years old children's emotional intelligence performance was developed through the ELT in the study. When the fact that emotional intelligence development is fixed at the age of 17 , is taken into consideration, development emotional intelligence of children, whose age is 10, through ELT is important. Because 10 years old is a period in which students experience transition between primary school and secondary school, late childhood and puberty. Therefore, 10 years old children are vulnerable to the factors disrupting social-emotional development (Keefer, Holden, \& Parker, 2013). Systematic and planned development of emotional intelligence performance of children during primary school period makes them more competent to cope with problems emerging in transitions between primary school and secondary school, late childhood and puberty.

Results of the study indicated that ELT increased significantly emotional intelligence performance of the experimental group students whereas the control group students' emotional intelligence performance did not increase. This significant difference is expected to stem from the ELT that is the independent variable of the study. During ELT, which lasted for eight weeks the experimental group's students were allowed to contemplate on their emotions, categorize, label, and express their emotions, care others' emotions, develop an awareness of social skills through previously established interactions each other. If emotional intelligence is an expression of social-emotional competency in long-term memory, possession of emotional intelligence skills can be developed through appropriate experiences, which are organized in classrooms. Furthermore, emotional intelligence skills can be reinforced and stabilized by appropriate experiences. Either long-term or short-terms achievements in experiences about emotional intelligence skills can pave the way of good and strong personality (Zeidner et. al., 2002). In ELT process, students underwent appropriate experiences through the classroom activities based on their previously interactions with each other. These appropriate and successful social-emotional experiences may be the first step in acquiring the good and strong personality. Therefore, teachers can design and employ emotional-literacy activities to compose positive classroom settings and decrease behavioural problems among students. On the other hand, school staffs, school workers aiming to increase socio-emotional learning develop school- 
based emotional literacy activities and carry out school-wide to establish better school climate and overcome behavioural problems.

Results of the study can be explained through Experiential Learning Theory developed by Kolb (1984). Experiential Learning Theory deals with learning as a process in which knowledge is acquired through experiential transformation. The learner must think on and be open to experiences in depth, conceptualize experience by comparing other experiences in terms of similarities and differences, develop problem-solving and decision-making skills. Questions such as "What did you realize? ", "Why did it happen? " are important to allow learners to contemplate on their experiences in depth. Contemplation on experience and its analysis enable learners to focus on experiences. Therefore, emotions are an inseparable part of learning (Kolb, 1984; Jacobson \& Ruddy, 2004;). In the ELT process the experimental group students were allowed to focus and think on their existing interactions with each other, left directly to socialemotional experiences, on the other hand, self-awareness, self-management, motivation, empathy, and social-relational skills were made more tangible by asking those directive questions. Therefore, emotional intelligence performance of the experimental group students was thought to be developed through experiential transformation.

Results about the follow-up of impact of ELT demonstrated that ELT increased permanently emotional intelligence performance of the experimental group students. Results of the study were supported by several research results in the literature (Greenberg \& Kushe, 1998; Jones, Brown, \& Aber, 2011; Reddy \& Richardson, 2008). Permanent impact of ELT can be explained through radical behaviourism developed by Skinner (1984). Skinner (1984) claimed in his theory that environment in which a specific behaviour occurs, and results of a behaviour are important in learning defined as permanent behaviour change. Skinner (1984) also argued that a specific response, which generates successful outcomes, is repeated in similar environments and stimulus. Therefore, learning is dependent on outcome and environment. In ELT process, behaviours of the students that are appropriate for emotional intelligence were reinforced and they were allowed to realize that those appropriate behaviours produced successfully and desired outcomes and inappropriate behaviours did not work in positive outcomes and led to failures. Thus the experimental group students who were aware of those appropriate behaviours for emotional intelligence, brought about positive and successful outcomes, may have made those behaviours permanent by repeating in the classroom and school environments.

Emmons (2000) stated that there is an interaction between emotional intelligence and spirituality, spiritual skills can be developed instructional activities that are similar to the emotional intelligence training. As a consequence, fostering emotional intelligence among the participant children can result in improvement of spiritual skills. Therefore, it can be said that developing emotional intelligence performance through the emotional literacy activities has a multifaceted outcome for primary school children.

\section{Limitations of the Study:}

- The ELT was designed for the $4^{\text {th }}$ grade primary school children. The ELT can be designed for $1^{\text {st }}, 2^{\text {nd }}$, and $3^{\text {rd }}$ grade primary school children, their impact can be monitored and revealed.

- The present study was designed in quasi experimental research with control group. Impact of the ELT can be explored through more robust experimental design in future research.

- The present study can be replicated with a larger population in future research.

- Impact of the ELT on 10 years old primary school children was investigated in the context of emotional intelligence. Impact of the ELT can be addressed in terms of different socialemotional skills concept such as social-skills, empathy, pro-social behaviour, emotional skills, emotion regulation, through different instruments. 


\section{Practical Implications}

- Developing emotional literacy training for all mandatory educational level allows social and emotional learning to be systematically dealt with from primary school to high school.

- In the present study impact of the ELT was investigated through experimental research that is one of the quantitative research methods. Impact of the ELT can be examined through phenomenological study, which is one of the qualitative research methods.

- Planned and systematic emotional literacy activities can develop students' sociorelational skills.

- Emotional literacy activities can improve students' skills in recognition and expression of their emotions.

- Teachers or other school staffs can increase empathic skills of students through emotional literacy activities.

- Results of the study revealed that the ELT increased participant student's emotional intelligence performance. In-service training can be developed to train teachers about how to design and conduct emotional literacy activities.

- Emotional literacy activities can be designed to foster spirituality skills among primary school children.

\section{Acknowledgments}

There is no funding body which supported the present stud and there is no conflict of interest between the authors. Furthermore, all necessary, official and ethical permissions were taken from the local education authorities before the present study was launched.

The present study is a part of doctoral dissertation of Impact of Emotional Literacy Training on Student's Emotional Intelligence Level in Primary Schools by Kerem Coskun conducted at Ondokuz Mayis University Graduate School of Education, under supervision of Yucel Oksuz.

\section{ORCID}

Kerem Coskun (iD https://orcid.org/0000-0002-3343-2112

Yücel Öksüz (D) https://orcid.org/0000-0001-9310-7506

\section{REFERENCES}

Arda, T. B., \& Ocak, S. (2012). Social Competence and Promoting Alternative Thinking Strat egies PATHS Preschool Curriculum. Educational Sciences: Theory and Practice, 12(4), 2691-2698.

Boyatzis, R. E., Goleman, D., \& Rhee, K. (2000). Clustering competence in emotional intelligence: Insights from the Emotional Competence Inventory (ECI). In R. Bar-on, J.D.A. Parker (Eds.), Handbook of emotional intelligence (pp: 343-362). San Francisco: Jossey-Bass.

Bredacs, A. (2010). emotional intelligence and its development in school-with a special view to talent management. Practice and Theory in Systems of Education, 5, 65-86.

Brown, R. B. (2003). Emotions and behavior: Exercises in emotional intelligence. Journal of Management Education, 27(1), 122-134.

Burman, E. (2009). Beyond emotional literacy in feminist and educational research. British Educational Research Journal, 35(1), 137-155.

Cohen, J. (1992). A power primer. Psychological Bulletin, 122, 155-159.

Cohen, L., Manion, L., \& Morrison, K. (2000). Research methods in education. Oxon: Taylor \& Francis Group. 
Coppock, V. (2007). It's good to talk! A multidimensional qualitative study of the effectiveness of emotional literacy work in schools. Children \& Society, 21(6), 405-419.

Coskun, K., Oksuz, Y. \& Yilmaz, H.B. (2017). Ten years emotional intelligence scale (TYEIS): Its development, validity, and reliability. International Journal of Assessment Tools in Education, 4(2), 122-133.

Di Fabio, A., \& Kenny, M.E. (2011). Emotional intelligence and perceived social support among Italian high school students. Journal of Career Development, 39(5), 461-475.

Dolev, N. (2012). Emotional Intelligence Competencies in Teachers through Group-Based Coaching. (Unpublished Doctoral Thesis). The University of Leicester, Leicester.

Domitrovich, C.E., Cortes, R.C. \& Greenberg, M.T. (2007). Improving young children's social and emotional competence: A randomized trial of the preschool paths curriculum. The Journal of Primary Prevention, 28(2), 67-91.

Dulewicz, V., Higgs, M. (2004). Can emotional intelligence be developed? The International Journal of Human Resource Management, 15(1), 95-111.

Emmons, R. A. (2000). Is spirituality an intelligence? Motivation, cognition, and the psychology of ultimate concern. The International Journal for The Psychology of Religion, 10(1), 3-26.

Faupel, A. (2003). Emotional literacy assessment and intervention ages 11-16. Southampton: Nfer-Nelson Publishing.

Ferrando, M., Prieto, M.D., Almeida, L.S., Ferrandiz, C., Bermejo, R., Lopez-Pina, J.A., Hernandez, D., Sainz, M., \& Fernandez, C. (2010). Trait emotional intelligence and academic performance: Controlling for the effects of IQ, personality, and self-concept. Journal of Psychoeducational Assessment, 20(10), 1-10.

Field, A. (2009). Discovering Statistics Using SPSS. London: Sage Publications.

Flynn, S.J. (2010). A comparative and exploratory study of the nfer-nelson emotional literacy scale in an Irish context (Unpublished Doctoral Dissertation). The University of Exeter, Exeter.

Fraenkel, F., Wallen, N.E., \& Hyun, H. (2012). How to design and evaluate research in education. New York: McGraw Hill.

Gillum, J. (2010). Using emotional literacy to facilitate organizational change in a primary school: A case study (Unpublished Doctoral Dissertation). The University of Birmingham, Birmingham.

Goleman, D. (1995). Emotional intelligence: Why it can matter more than IQ. New York: Bantam Books.

Goleman, D. (1998). Working with emotional intelligence. New York: Bantam Books.

Greenberg, M.T., \& Kushe, C.A. (1998). Preventive intervention of school-age deaf children: The paths curriculum. Journal of Deaf Studies and Deaf Education, 3(1), 49-63.

Haddon A, Goodman H, Park J, \& Crick R.D. (2005). Evaluating Emotional Literacy in Schools: The Development of the School Emotional Environment for Learning Survey. Pastoral Care in Education, 23(4), 5-16.

Hallam, S. (2009). An Evaluation of the social and emotional aspects of learning (SEAL) program: Promoting positive behaviour, effective learning and well-being in primary school children. Oxford Review of Education, 35(3), 313-330.

Hamre, B. K., Pianta, R. C., Mashburn, A. J., \& Downer, J. T. (2012). Promoting young children's social competence through the preschool PATHS curriculum and MyTeachingPartner professional development resources. Early Education \& Development, 23(6), 809-832.

Jacobson, M., \& Ruddy, M. (2004). Open to outcome: A practical guide for facilitating and teaching experiential reflection. Oklahoma: Wood'N'Barnes Publishing. 
Jellesma, F.C., Rieffe, C., Terwogt, M.M., Westenberg, M. (2011). Children's sense of coherence and trait emotional intelligence: A longitudinal study exploring the development of somatic complaints. Psychology \& Health, 26(3), 307-320.

Jones, S.M., Brown, J.L., \& Aber, L.J. (2011). Two-year impacts of universal school-based social-emotional and literacy intervention: An experiment in translational and developmental research. Child Development, 82(2), 533-554.

Keefer, K.V., Holden, R.R., \& Parker, J.D.A. (2013). Longitudinal assessment of trait emotional intelligence: measurement invariance and construct continuity from late childhood to adolescence. Psychological Assessment, 25(4), 1255-1272.

Kelly, B., Longbottom, J., Potts, P., Williamson, J. (2004). Applying Emotional Intelligence: Exploring the Promoting Alternative Thinking Strategies Curriculum. Educational Psychology, 20(3), 221-240.

Kolb, D.A. (1984). Experiential learning: Experience as the source of learning and development. New Jersey: Prentice Hall.

Lu, C., Buchanan, A. (2014). Developing students' emotional well-being in physical education. Journal of Physical Education, Recreation \& Dance, 85(4), 28-33.

Matthews, B. (2006). Engaging education: Developing emotional literacy, equity and coeducation. Berkshire: Open University Press.

O'Hara, D. (2011). The impact of peer mentoring on pupils' emotional literacy competencies. Educational Psychology in Practice, 27(3), 271-291.

Orbach, S. (1998). Emotional literacy. Young Minds Magazine, 33, 12-13.

Paek, E. (2006). Religiosity and perceived emotional intelligence among Christians. Personali ty and individual differences, 41(3), 479-490.

Park, J. (1999). Emotional literacy: Education for meaning. International Journal of Children's Spirituality, 4(1), 19-28.

Perry, L., Lennie, C., \& Humphrey, N. (2008). Emotional literacy in the primary classroom: teacher perceptions and practices. Education 3-13, 36(1), 27-37.

Pratt, L. (2009). Supporting pupils at risk of exclusion: an evaluation of an intensive, out of school, emotional literacy program for key stage 3 pupils (Unpublished Doctoral Thesis). Institute of Education, University of London, London.

Qualter, P., Whiteley, Y., Hutchinson, J.M., \& Pope, D.J. (2007). Supporting the development of emotional intelligence competencies to ease the transition from primary to high school. Educational Psychology in Practice, 23(1), 79-95.

Reddy, L.A., \& Richardson, L. (2006). School based prevention and intervention programs for children with emotional disturbance. Education and Treatment of Children, 29(2), 379404.

Rivers, S.E., Brackett, M.A., Reyes, M.R., Mayer, J.D., Caruso, D.R., \& Salovey, P. (2012). Measuring emotional intelligence in early adolescence with the MSCEIT-YV psychometric properties and relationship with academic performance and psychosocial functioning. Journal of Psychoeducational Assessment, 30(4), 344-366.

Saltalı, N. D. (2010). Duygu eğitiminin okul öncesi dönem çocuklarının duygusal becerilerine etkisi (Unpublished Doctoral dissertation) Selçuk University, Institute of Social Sciences. Retrieved from http://acikerisim.selcuk.edu.tr:8080/xmlui/bitstream/handle/123456789/ 7044/258519.pdf? sequence=1\&isAllowed=y

Shapiro, S.S. \& Wilk, M.B. (1965). An analysis of variance test for normality (complete samples). Biometrika, 52(3), 591-611.

Skinner, B.F. (1984). Selection by consequences. Behavioural and Brain Sciences, 7, 477-481. Steiner, C. (1979). Emotional literacy: Intelligence with a heart. California: Personhood Press. 
Tabachnick, B. G., \& Fidell, L. S. (2007). Using multivariate statistics. Allyn \& Bacon/Pearson Education.

Tew, M. (2007). School effectiveness: Supporting success through emotional literacy. London: Sage Publications.

Tufan, Ş. (2011). Geliştirilen duygusal zekâ ĕgitim programının ortaöğretim dokuzuncu sınıf ögrencilerinin duygusal zekâ düzeylerine etkisi. (Unpublished master thesis). Ankara University, Institute of Educational Sciences.

Yaşarsoy, E. (2006). Duygusal zeka gelişim programının, eğitilebilir zihinsel engelli ögrencilerin davranış problemleri üzerindeki etkisinin incelenmesi. (Unpublished master thesis). Çukurova University, Institute of Social Sciences.

Zeidner, M., Roberts, R.D., \& Matthews, G. (2002). Can emotional intelligence be schooled? A critical review. Educational Psychologist, 37(4), 215-231. 